Running head: NATURAl Law, Non-Voluntary Euthanasia AND Public Policy

\title{
NATURAL LAW, NON-VOLUNTARY EUTHANASIA AND PUBLIC POLICY
}

\section{Joseph Drew}

Institute for Public Policy and Governance, University of Technology Sydney

\section{Bligh Grant}

Institute for Public Policy and Governance, University of Technology Sydney 


\section{ABSTRACT}

Natural law philosophy asserts that there are universally binding and universally evident principles that can be determined to guide the actions of persons. Moreover, many of these principles have been enshrined in both statute and common law, thus ensuring their saliency for staff and institutions charged with palliative care. We examine the often emotive and politicized matter of (non-voluntary) euthanasia - acts or omissions made with the intent of causing or hastening death - with reference to natural law philosophy. This leads us to propose a number of important public policy remedies to ensure dignity in dying for the patient, and their associates.

Keywords: Palliative Care, Natural Law, Principle of Double Effect, Non-Voluntary Euthanasia.

\section{INTRODUCTION}

Natural Law philosophy asserts that there are universally binding and universally evident ends which apply to all persons (Drew and Grant, 2017). It is argued that these ends can be arrived at through the application of reason and (to a lesser extent) through the observation of nature and this is, in fact, the common form of justification made to secular audiences (Hittinger, 2003). Indeed, the existential ends of persons occupy a central position in natural law ethics. These ends include inter alia 'human life, the union of male and female, care of one's children,[and] a well ordered society' (Velasquez and Brady 1997, p. 87). Thus, for persons operating from a Natural Law perspective human life is considered to be of value, in and of itself, and the implied prohibition on taking human life is considered to form the foundation of all social interactions (Finnis, 2013a). Moreover, this value which is placed on human life protects all persons equally. Three other important propositions guide much of the thought associated with Natural Law - 'dignity', 'common good' and 'solidarity'. Dignity in Natural Law differs somewhat to the colloquial use of the term and refers to the inherent right of individuals to pursue their existential ends (Messner, 1952). The common good refers to the help accruing to individuals, as a result of co-operation, in pursuit of their existential ends (such as caring for those unable to care for themselves) whilst solidarity acknowledges that all 
persons are part of a single human family which shares in rights and mutual obligations (Boileau, 1998).

Natural Law has an important place in both Catholic Social Teaching (CST) and the development of judicial law. However, it would be quite wrong to think of Natural Law as a purely Christian theology - first, because Natural Law can be traced back to at least the work of Aristotle and, second, because it has been argued that all three monotheistic faiths (Judaism, Islam and Christianity) have a Natural Law tradition (see, Emon, Levering and Novak, 2015). The principle of double effect - derived from Natural Law precepts - has been a standard tool for assessing both the morality and legality of acts or omissions which end in the death of palliative patients. Natural Law precepts have also been used to evaluate the morality of acts or omissions conducted with the intent of causing death. The principles are often appealed to in public policy debates regarding the emotive issue of euthanasia (see, for instance, Beabout, 1989).

As we saw in the previous chapter in this 'Special Edition' of Research in Ethical Issues in Organisations (Kennedy and Kennedy 2018) the issues of euthanasia and assisted suicide have long and controversial histories, inclusive of debate surrounding a bill to legalize the act (subsequently defeated) in the House of Lords in 1936; Germany legalizing euthanasia as an act of mercy killing in the cases of very young infants born with severe deformities in 1938, and a surge for support for the acts commensurate with the advent of HIV/AIDS in the early 1980s (see Kennedy and Kennedy 2018). In Australia, the bicameral parliaments of the sovereign state jurisdictions of Victoria and New South Wales (NSW) have very recently assented to voluntary assisted dying bills (see NSW Government 2017; Victoria State Government 2017) following on from legislation that was previously passed in the Northern Territory in 1994 - but subsequently overturned by the Australian Government in 1997 - and ultimately unsuccessful bills for similar legislation in the states of South Australia in 2016 and Tasmania in 2016 (see Kennedy and Kennedy 2018). This follows from recent similar legislation in Holland and Belgium (again, see Kennedy and Kennedy 2018). As such, the issues of euthanasia and assisted suicide are very much topical.

The balance of this journal article is organised as follows. First, we review Natural Law perspectives on human life, the principle of double effect and non-voluntary euthanasia. Next, in response to Foot's $(1978$, p. 31$)$ concession that 'in real life the certainties postulated by 
philosophers hardly ever exist' we provide a brief overview of a real-life instance of palliative care. We then apply our understanding of the principle of double effect and Natural Law perspectives on dying to the facts of the case study to further explicate matters. The article concludes by outlining important public policy recommendations aimed at respecting the dignity of all involved in death and dying.

\section{NATURAL LAW, PRINCIPLE OF DOUBLE EFFECT AND NON-VOLUNTARY EUTHANASIA}

Natural Law is preoccupied with 'existential ends', 'dignity', 'solidarity' and the 'common good' and it is asserted that these matters can be recognized by applying reason and observing nature. Some religious traditions also claim that Natural Law is revealed in sacred texts although it is rarely argued that revelation of this type is necessary for one to assent to reason (Hittinger, 2003; Emon, Levering and Novak, 2015; Messner, 1952). Natural Law in CST can be traced back to the commentaries of Aristotle's Metaphysics, Politics and Ethics, produced by Thomas Aquinas in the seventh and eighth decades of the thirteenth century (Finnis, 2004). The 'existential end' which is most important to us in our present quest to understand the particular constraints and expectations regarding the treatment of palliative patients is the end of 'human life'. In this regard, it is important to understand that human life differs to other life. True, humans experience all the urges which prompt other animals to act - the drive to procreate, care for young and survival - however, Natural Law asserts that persons alone can perceive the inherent ends of such urges (Messner, 1952). Thus, persons are fundamentally different to vegetables or goats - not because they look different, but because they have a capacity to integrate their spiritual self and pursue ends not visible to other biological life. Indeed, it has been noted that the term 'vegetative state' seeks to diminish a person's humanity and in so doing 'deny the personhood of these invalids by breaking off human solidarity with them at the root' (Finnis, 2013b, p. 321).

An important principle arising from Natural Law is the Principle of Double Effect (PDE), which not only has saliency to Christian morality but is also embedded in the common law tradition inherited from the British and recent statutes enacted in Queensland, Australia (upon which our case study is based; McGee, 2004). The PDE derives from an inquiry by Aquinas as to whether it might be lawful to kill a man in self-defense, articulated in Summa Theologica 
Q64, Article 7. Aquinas' (1989) answer is enlightening and bears repeating at length, given the important contribution it made to subsequent moral theory and common law:

\begin{abstract}
Nothing hinders one act, from having two effects, only one of which is intended, while the other is beside the intention. Now moral acts take their species according to what is intended, and not according to what is beside the intention...And yet, though proceeding from a good intention, an act may be rendered unlawful if it be out of proportion to the end. (Summa theologiae, question 64, article 7).
\end{abstract}

Thus, PDE is entirely consistent with the first precept of Natural Law (i.e., That Good is to be done and pursued, and evil is to be avoided (Aquinas, 1989, Summa Theologiae, 1-2, Question 94, article 2)). That is, the intended effect (the pursuit of good) - rather than the actual effect is at the heart of PDE moral evaluation for Aquinas. Yet Aquinas is a realist: he understands that the world is an uncertain place and that acts committed with a certain intent can often go awry and result in bad 'side-effects'. Aquinas in no way proposes that persons should give no thought to the foreseeability of a bad side-effect, but rather he insists that the intended good must be sufficiently grave to warrant the possibility of the bad side-effect. Specifically, in the example put forward by Aquinas, the good (preserving the defenders 'end' of human life) can only justify a bad side-effect (the death of the assailant) if the defender takes all pains to use only 'necessary violence' to achieve the intent of saving the defenders life (Aquinas, 1989).

Drew et al. (2017) provide a careful review of the various formulations of PDE and propose the following definition:

\footnotetext{
It is morally permissible to undertake an action when one foresees that the undertaking may bring about at least one state of affairs, such that, if this state of affairs were intrinsic to the action undertaken, the action would be rendered impermissible, if and only if (i) the 'bad' state of affairs is not intended but brought about as a side-effect (and that all efforts have been made to mitigate the undesired side-effect) and (ii) there is a proportionally grave reason for undertaking the action.
}

This formulation places front-and-center the ideas of foreseeability, proportionality and intent. There is an important distinction between bad side-effects that are foreseeable or even probable and bad side-effects that are definite. When a bad side effect is definite, there is no perceptible difference between 'means' and 'ends', and as a result this would allow the PDE to be used as 
a mere ex post excuse tool. It would also allow the sanctity of human life to be routinely violated where good 'ends' were to be achieved through the 'means' of persons and would result in abhorrent outcomes (for instance, without the distinction between foreseeable and definite bad side-effects it would be permissible to harvest multiple organs from a live donor to save multiple lives). The formulation proposed by Drew et al. (2016) also preserves the substance of Aquinas' articulation - that bad side-effects can only be countenanced when a sufficiently grave reason exists for taking the action. That is, we shouldn't condone significant bad-effects for relatively trivial matters.

Intent is the matter at the forefront of most criticisms of PDE - specifically the question regarding how an external observer can assess intent. This is a rather strange criticism given that human ability to assess intent lies at the heart of our judicial system and indeed most human interactions - if we deny that it is possible for external observers to assess intent then our whole system of judicial correction and indeed the ready forgiveness we extend in the case of 'accidents', could no longer be considered tenable (Finnis, 2013a). Moreover, there are a number of ways in which we might uncover intent. For instance, one could simply question the agent regarding their intent - however, philosophers proposing clever, but generally implausible, scenarios have shown that this will not work in a range of situations (for instance in the case of the 'irresponsible agent' who does not ponder the reasons for acting (Beabout, 1989) or the 'philosophically sophisticated agent' who prevaricates (Quinn, 1989)). An advance on this approach is to ask the agent whether they would consider that their plan had been carried out if the bad side-effect did not eventuate. In addition, Drew et al. (2017) have put forward the proposition that intent can be evidenced by the actions which an agent takes to mitigate foreseen bad side-effects and also how the agent responds to any altered circumstances (should they occur) and have built this proposition into their formulation of PDE.

Intent is critical to PDE, for at least two important reasons. First, consonant with aretaic ethics (which have a clear influence on Aquinas' work) 'a person becomes virtuous through habitually intending good acts' - that is, it is the intent which makes a person good, not the result (Beabout, 1989, p. 50). Thus even if we were unable to discern intent, PDE would still occupy an important place in moral theory (if not in law). Second, intent is important because if the bad-effect is the aim of an act, then it is far more likely to eventuate (because as we have noted the agent will change their behavior if circumstances change which would otherwise deny them of their objective; Drew et al. 2016). This question of intent is particularly important in the 
process of dying - because if death is intended, rather than merely foreseen, then the whole moral and legal evaluation changes dramatically.

Acts or omissions with the intent of causing death are properly termed euthanasia and are currently deemed in law (at least in Queensland) to be murder or manslaughter (Finnis, 2013a; Craig 1994; Garrard and Wilkinson, 2005; McGee, 2004). A recent publication by the Australian Human Rights Commission (2016, p. 3) defines euthanasia as 'the process of intentionally terminating a person's life to reduce their pain and suffering' ${ }^{\text {. Sometimes a }}$ distinction is said to exist between acts intended to extinguish human life and omissions intended to extinguish human life (see, for instance McLachlan, 2008) - however, Finnis (2013), Craig (1994), and McGee (2004) all note that the distinction is rather meaningless; it is the intent of killing which makes an agent both morally and legally responsible ${ }^{2}$. We need only consider a simple scenario to intuitively understand that it is the decision that a human should die which is the salient fact - not the method of death. For instance, consider the death of a baby through (a) a caregiver's neglect to feed and attend to hygiene or (b) deliberately smothering the baby. In both instances, it is the decision to deliberately kill a human - more so a human which depends on others for survival - that attracts our moral and legal condemnation. Indeed, the former case (neglect) may well attract greater condemnation because it requires a clear resolve (multiple decisions) to kill over a lengthy period of time in the face of what would likely yield cries of obvious human suffering.

When we consider euthanasia, we must also recognize that it is based on a judgement that some kinds of human life are not worth living which sets up a 'new structure of radical inequality' within the human species which may well set us on the slippery slope which resulted in the 'Nazi horrors' wherein some humans took upon themselves the role of classifying which lives "“are worth living" or "not worth living", (Finnis, 2013, p. 268; see also the seminal work of Lifton, 1986). This, of course, is not only disturbing - as evidenced by the fact that euthanasiasts never extend their arguments to the profoundly disabled, newborns (such as those afflicted with the terminal and excruciating Cri de Chat) or the mentally ill - but also directly violates Natural Law.

\footnotetext{
${ }^{1}$ The Australian Human Right Commission publication is restricted to voluntary euthanasia issues.

${ }^{2}$ Indeed, Abrams (1978, p. 262) in defending the distinction is forced to concede that 'the question of the means of death (active versus passive) arises only after the decision that death itself is what is preferable' - that is, plainly the key decision is the decision to kill. Notably, Abrams (1978, p. 262) concludes that 'active euthanasia is preferable to passive euthanasia'.
} 
However, there are some important distinctions which must be made in relation to the context of euthanasia: namely the distinction between voluntary, non-voluntary and involuntary euthanasia events. Persons advocating for euthanasia invariably have in mind the freedom for competent adults to choose the manner of their death - voluntary euthanasia. This is a context in which it is prima facie possible to mount an ethical case which might receive public assent - and indeed these arguments were present in political debates in NSW and Victoria in 2017; in South Australia and Tasmania in 2016 and in the Northern Territory in 1994 (see Kennedy and Kennedy 2018). (Although when one takes cognizance of the fact that even voluntary euthanasia makes distinctions and assertions regarding types and worth of human life - and the effect that this must have on those who live in similar circumstances - then the arguments are not quite as innocuous as they may at first appear to be). By way of contrast, non-voluntary euthanasia occurs when the person has not (or is unable to) communicate their wishes - in this case, other humans must presume to be able to know how the person would think and feel about terminating their life, in addition to making classifications and judgements regarding the worth of various human lives. Few would presume to argue for this position. At the furthest distance from Natural Law conceptions on human dignity, we have involuntary euthanasia - where the person does not want to die, but their wishes are ignored.

We now proceed to relate a case study from public documents relating to the death of a person over the age of 90 in the State of Queensland Australia, in order that we might further explicate on salient matters.

\section{A CASE STUDY IN DYING}

The following material is a redaction of a Queensland Courts, Office of the State Coroner report. All efforts have been made to ensure anonymity (the patient is referred to simply as $\mathrm{X}$ and gender along with specific location is not disclosed). The purpose of recounting real-life events is to: (i) ensure that our latter inquiry is not open to the charge of being a cleverly devised, but implausible, scenario developed by philosophers entirely with the objective of proving a point (see, Foot, 1978), and (ii) underline the importance of our inquiry in response to a public policy issue which really occurs and really does require immediate remedial attention.

' $[\mathrm{X}]$ was a [90 plus year old person] with a background history of dementia, hypertension, ischaemic heart disease, depression and osteoarthritis...[X] was described by carers and [X's] GP as a frail [person] with dementia who was pleasantly confused and wandered - often 
exhibiting "exit-seeking" behaviours and requiring some re-direction. [X] had also had a number of falls in the 12-18 months prior to [X's] death due to [X's] propensity to wander....

On [date] $[\mathrm{X}]$ was transferred to the ...Hospital after suffering a stroke....CT scanning was done in the early stages. There was no acute bleed however it was too early to detect ischaemic change. Clinically however it was apparent that X had suffered a large left cortical stroke which had caused a dense right hemiplegia (weakness/loss of power) and affected X's language centre. X had right sided neglect (failure to recognize self or anything on [X's] right side) and receptive as well as expressive dysphasia/aphasia (reduced ability to understand commands and inability to speak). X was repeatedly assessed by the speech pathologist who monitored this (no improvement) as well as monitored X's ability to swallow. The speech pathologist recorded that $\mathrm{X}$ had significant oropharyngeal dysphagia (inability to process foods or liquid in the mouth due to weakness of the tongue and swallowing musculature) and therefore deemed $\mathrm{X}$ as being unfit for feeding, recommending X remain "nil by mouth" to prevent aspiration (food/fluid entering the lungs).

$\mathrm{X}$ was initially managed with intravenous fluids, which were switched to subcutaneous fluids. In the initial days of X's admission X was drowsy and difficult to rouse. X's oropharyngeal weakness notwithstanding this also made attempts at feeding hazardous. A feeding tube was inserted on 17th June for administration of medication (and not nutrition) as discussed with X's family. The reasoning was that there was a very high risk of aspiration if supplemental nutrition was given in a drowsy patient.

Review by the speech pathologist [date] revealed that X had right inattention although [X's] eyes were open; right facial droop, nil verbal response and still had severe dysphagia such that [X] remained a high aspiration risk. This was unchanged on [date] and the clinical nurse consultant documented that all of the therapists (speech pathologist, physiotherapist and occupational therapist) all agreed that $\mathrm{X}$ was unlikely to improve.

[A family meeting was then conducted at which the majority of the family asked for the nasogastric tube to be removed. However, no decision was made regarding fluid provision and one family member raised concerns that the cessation of fluids was indeed passive euthanasia and unlawful].

Family felt that $\mathrm{X}$ would be more comfortable in [aged care facility] and requested transfer the next day. Treating staff told family that subcutaneous fluids would continue (at $42 \mathrm{ml}$ hour- i.e. 1 litre in 24 hours) until transfer time and then would be ceased with any decision re: continuing fluids at the nursing home to be at their discretion.

What has occurred in X's case is withdrawal of treatment in the context of futility in continuing active treatment in a [person] who has suffered a massive stroke from which [they] would not recover any functionality. $[\mathrm{X}]$ could not safely be fed and as withdrawal of nasogastric feeding 
was agreed it would be expected that $[\mathrm{X}]$ would die. This is not euthanasia and accords with good medical practice in terms of caring for the dying. I therefore have no concerns regarding her management.

There is no record of $\mathrm{X}$ being treated for pain or being assessed as experiencing pain or suffering.

Records further indicate that the patient died just over 5 days after being returned to the aged care facility.

\section{PRINCIPLE OF DOUBLE EFFECT}

As we have noted, the PDE provides an important moral and legal defense for when an act or omission yields a bad side-effect contrary to the good intent of the agent. As such, PDE pragmatically recognizes that we live in an uncertain world, and that agents are often faced with decisions which may resolve into a number of effects. Key to assessing acts or omissions under PDE are the ideas of intent, foreseeability and proportionality.

In the case study related above three events seem to be critical to deciding whether acts or omissions were morally (and legally) licit, namely:

1. The decision to remove the naso-gastric tube

2. The decision to remove the intravenous fluids

3. The decision to remove the sub-cutaneous fluids

Before we can assess each act, we must first investigate whether the patient was a suitable candidate for palliative care in the first instance. Dr Gillian Craig (1994, p. 140), formerly a consultant Geriatrician in Northampton, has written persuasively against the practice of denying fluids to palliative patients and astutely notes that 'no doctor's judgement is infallible when it comes to predicting how close a patient is to death... to say that it is a matter of days, and to treat by this method, is to make the prediction self-fulfilling'. Therefore, even in the case where medical consensus is that a patient will probably shortly die the act or omission of denying fluids ensures that the patient will definitely die within a period of two to seven days (as conceded by the Queensland Coroner). Unless there can be a certainty - not a mere probability - that the patient will die in a period under two days, then it is impossible to know ex ante whether the cause of death will be the illness or the denial of fluids. 
In the case of $\mathrm{X}$, there does not appear to be any reason to think that the patient would die in a period of under two days. Indeed, it is hard to explain why the patient was considered palliative at all. The Coroner's report refers to a 'large left cortical stroke' but concedes that the CT showed 'no acute bleed'. The diagnosis seems to have been solely on the basis of physical examinations by the Resident, a speech pathologist and a palliative care specialist. Mindful of Dr Craig's (1994) observation that no doctor is infallible - an observation that many of us have confirmed by experience - in the absence of objective evidence we cannot be sure that some of the symptoms such as weakness and confusion were not due to underlying pathologies (after all the Coroner reports that $\mathrm{X}$ was frail and suffered from dementia). Even if all the symptoms were due to the stroke, it is hard to understand why a stroke - large as it might have been would be classified as a terminal condition.

Notably, the Coroner makes much of X's age, frailty, dementia and depression (indeed the Coroner notes that $\mathrm{X}$ had previously spoke of a desire 'to go home to Heaven') ${ }^{3}$. The question that we might reasonably ask is whether a stroke in a far younger person would be considered to be a terminal illness. We doubt that any medical justification for deeming a stroke of this severity to be terminal can be found - clearly a further stroke might result in death, but if nutrition, fluids and hygiene had been provided to $\mathrm{X}$, then it is hard to see why $\mathrm{X}$ might have been deemed a suitable candidate for palliative care. In view of the heavy and repeated emphasis placed on the age, dementia and depression of $\mathrm{X}$, it seems that the Coroner was acutely aware of the fact that the stroke, in and of itself, would not otherwise be considered a terminal condition. Indeed, the Coroner concludes that $\mathrm{X}$ ' $h a[d]$ suffered a massive stroke from which [they] would not recover any functionality' - notably, the conclusion is not that X had suffered a massive stroke from which they would die.

The fact that $\mathrm{X}$ does not seem to have suffered from a terminal illness, has an important effect on the proportionality of the three events which we consider.

The first event was the removal of the naso-gastric tube which we are told was only for delivering medication. The medication in question was anti-coagulant delivered to reduce the likelihood of a further stroke. The good intent of this act was presumably to reduce the discomfort for the patient arising from the naso-gastric tube (use for periods of less than one

\footnotetext{
${ }^{3}$ Incidentally, it seems rather odd that the Coroner would mention a desire to 'go home to Heaven' at all. It is in no way an expression of a desire to be euthanised or a clinical symptom of a terminal illness - rather it is a common creed expressed by Christians and $\mathrm{X}$ was a patient at a Christian aged care facility.
} 
month are indicated; Pearce and Duncan, 2002 ${ }^{4}$ ). The foreseeable bad side-affect was a greater likelihood of subsequent stroke which might have resulted in death. Moreover, it might be noted that whilst the tube was being used solely to deliver medications, it could also have been used to deliver fluids and nutrition. It is hard to argue that the bad-side effect (possible death) was proportional to the good of avoiding some discomfort.

The second event was the decision to remove IV fluids. It is hard to imagine what the good intention might have been - IV's ordinarily have to be changed every 3 days or so, but there are established protocols for dealing with this. Having an IV in would not have prevented transport to the aged care facility (moreover, the decision to transfer $\mathrm{X}$ had not been made at this stage). In addition, there is absolutely no reason why the nursing staff and visiting doctors at the aged care facility could not perform and maintain an IV (Craig, 1994). One can only imagine that the IV (and maintenance of same) was considered to cause some discomfort. The bad side-effect (death) is definite in a person who is unable to orally take fluids and nutrition in the absence of (the previously removed) naso-gastinal tube or IV. Because it is definite rather than merely foreseeable or probable, there is no real distinction between means and ends in this scenario. Moreover, an act which will definitely cause death could hardly be considered proportional to the discomfort of having an IV maintained.

The third event was the decision to remove the subcutaneous fluids. The Coroner wrote that Subcutaneous fluids are not life saving or life preserving and are a temporising measure of "life preservation". Prima facie the Coroner's statement is a self-contradiction: it both asserts that sub-cutaneous fluids are not life preserving and that they are also a measure of life preservation. Presumably, the key word is temporizing. Once again, it is hard to understand what the good intent might have been - perhaps alleviating discomfort. With respect to foreseeability the removal of the subcutaneous fluids - in the absence of any other measure to deliver fluids - could only result in one outcome (death). Therefore the distinction of 'sideeffect' versus intended effect is rather meaningless. Consonant with our analysis of the second act, the good intent of relieving discomfort is not proportional to the bad effect of death, no matter how temporizing the provision of subcutaneous fluids may have been. Moreover, as Craig (1996, p. 149) notes 'even when death is inevitable, the simple and safe measure of a

\footnotetext{
${ }^{4}$ In this case study use of a naso-gastric tube for a period of up to one month would have provided fluids and nutrition for a period well beyond the actual death date. For longer - and indeed indefinite - periods Pearce and Duncan (2002, p. 201) nominate percutaneous endoscopic gastromy tube as 'the method of choice' noting that it is both 'safe and cost-effective'.
} 
subcutaneous infusion may not be futile' - not least because the appearance of providing some fluids - no matter how temporizing they might be - provides relatives (particularly those uncomfortable with denying palliative patients the necessities of life) some assurance that death is due to the illness, not as a result of deprivation.

The fact that the only conceivable good intent of the first three acts leading to X's death were relatively trivial immediately raises the suspicion that removal of means (and potential means) of hydration was in fact motivated by a 'bad' intent - specifically, the intent to hasten the death of $\mathrm{X}$. It is important to remain cognizant of the fact that $\mathrm{X}$ was not being treated for pain, was not assessed to be suffering, and may not even have been palliative. Barry (2004, p.164) notes that the Papal allocution on caring for persistently unconscious - framed in terms of Catholic Social Teaching on Natural Law - 'has drawn a clear line in the sand and taught that the deliberate withholding or removal of food and water from these patients cannot be done without an intention to bring death upon them'. As we have seen Craig (1994, p. 140) echoes this sentiment in stating what could hardly be more obvious - that prolonged periods 'without hydration or nutrition will end in death, whatever the underlying pathology'. Moreover, the Coroner concedes that 'as withdrawal of nasogastric feeding was agreed it would be expected that $\mathrm{X}$ would die'. As we have noted, this is rather problematic given that the acts did not fit within the PDE, which is the common law defense for death caused by acts or omissions by medical personal pursuing putatively good intents. It is also notable that the recent amendments to the Queensland Criminal Code (1899) do nothing to invalidate the PDE as a legal principle (McGee, 2004). In fact the amendment specifically states:

Nothing in this section authorizes, justifies or excuses- (a) an act done or omission made with intent to kill another person (Queensland Criminal Code, 1899, s282A, s(3)).

Therefore, in the absence of any credible evidence of a substantive 'good' it is hard to understand how the first three acts could be either morally or legally licit. 
If the intent of the various acts was to bring about death, then according to most definitions, the acts were a case of euthanasia (Craig, 1994; McGee, 2004; Barry, 2004; Finnis, 2013a; Australian Human Rights Commission, 2016). For the Coroner, to declare that the events were 'not euthanasia and accords with good medical practice in terms of caring for the dying', means that the Coroner must: (a) believe that a stroke is a terminal condition, and (b) that persons involved in denying fluids did not believe that doing so would bring about death. We might also remain cognizant of the fact that $\mathrm{X}$ could indeed drink, but was declared nil by mouth because of the risk of aspiration, which might lead to death - therefore it seems, oddly enough, that in order to prevent aspiration and possible death, $\mathrm{X}$ was denied oral fluids which (in the absence of any other mechanism of hydration) would result in death.

Two important matters must still be addressed. First, we need to investigate whether the provision of fluids and/or nutrition is a medical procedure and, second, we must determine whether the provision of fluids and nutrition is futile in the case of a palliative patient.

The distinction regarding whether provision of fluids and nutrition is a medical procedure is important lawfully and morally because a patient does have the right to refuse aggressive medical treatment (although, of course in this case $\mathrm{X}$ was in no position to express his or her wishes, and X's family disagreed about what X's wishes might have been). Barry (2004, p. 156) writing on the allocution of Pope John Paul II states that 'the Holy Father declared that the provision of artificial nutrition and hydration was not a medical treatment, but was 'basic' or 'normal care' and that there was a moral obligation to provide it to the persistently unconscious'. Similarly, Finnis (2013b, p. 319) writing from the perspective of Natural Law asserts that naso-gastric tubes do not represent a medical procedure because "no distinctly medical skills are needed to insert a nasogastric tube or maintain the supply of nutrients through it'. A similar case could be made for IV lines - many farmers have had to provide fluids or medication through such means - including, the first author of this chapter, who has done so to treat milk fever in dairy animals. Indeed, one can even 'YouTube' instruction in both procedures! Moreover, the 'artificial' provision of fluids and nutrition is a regular occurrence. For instance, mothers unable to breast feed, routinely prepare formula for babies and employ tools (a baby bottle) to deliver the nutrition. A newborn left to their own devices could not sustain themselves, nor are they capable of giving or withholding consent. The similarities to the provision of nutrition to the persistently unconscious, or aphasic adults with oropharyngeal dysphagia are remarkable. Yet no-one would consider for a moment that providing artificial nutrition to a newborn is an aggressive medical procedure. Moreover, as we noted earlier, even 
when the newborn is dangerously premature, disabled or even terminal, few would consider for a moment that the newborn should be denied fluids, nutrition and hygiene care. This seems to suggest that it is not the act of providing fluids and artificial nutrition, alone, that is at the root of why some would consider a distinction between feeding a baby and feeding an aphasic or persistently unconscious person. The only conclusion would appear to be that at least two categories of humans are involved in the two scenarios. As noted earlier this sort of categorization denies human solidarity.

The Coroner also makes a claim that the context was one of 'futility'. Natural Law traditions (including Catholic Social Teaching) allows patients to decline futile treatment or treatment that comes with a heavy physical or spiritual burden. However, to declare a medical intervention to be 'futile' one must first decide that the intervention is a medical treatment aimed at restoration or improvement in health. For example, a naso-gastric tube delivering medication (only) might be removed if it was considered that the medication was having no therapeutic value. However, means of delivering fluids and nutrition can never be deemed 'futile' because they do not have a therapeutic goal - the goal is to sustain life, not to improve health.

Additional problems are posed in the case of non-voluntary euthanasia events, where the patient is conscious, but unable to communicate their wishes. In this instance, as we have discussed, others must presume to know the patient's views on end-of-life treatment, and the level of pain and suffering that they feel, in addition to making judgements about whether a particular kind of human life is, or is not, worth living. To make matters worse, a conscious but aphasic patient might be well aware of the decisions which are being made on their behalf, and this might cause significant mental anguish - especially if the patient does not agree to what is being done. Even if the patient does agree with the course of action being advocated on their behalf, they may feel mental anguish that others are being forced to make difficult decisions, which may haunt the decision-makers for many years to come. If there is dissent within the group of family and friends then the patient may well become aware of the dissent - if only through the atmosphere of tension which pervades when the family are present at the patient's bedside. It is no stretch of the imagination to consider that dissent may resolve into broken relationships, and thoughtless or angry words uttered in the emotionally charged environment of a 'death watch'. A conscious palliative patient may then be forced to grieve over the discord elicited from their treatment, in addition to grieving for their own demise. This would seem to be an extraordinarily cruel death - far removed from the 'good death' proposed by euthanasists. 


\section{PUBLIC POLICY REMEDIES}

Natural Law establishes an ethical framework for making decisions about the process of dying. Causing death, when this is not the intent of the act is morally and legally licit (assuming no case of negligence). Intending death is (under Natural Law) morally and (under statute and common law in Australia) currently legally illicit. When acts and omissions can only lead to death then the difference between side-effects and goals ceases to have any meaning and the principle of double effect is no longer relevant. When acts and omissions leading to death are directed at no substantive good, then it is very difficult to believe that the intent is anything other than to kill. To intentionally kill a palliative patient is to commit euthanasia. When the patient has not given their consent to the acts and omissions intended to bring about their death, then the euthanasia event is non-voluntary or involuntary. At the root of any euthanasia decision is the categorization of some life as 'worth living' or 'not worth living'. When palliative patients are subjected to non-voluntary euthanasia then in addition to breaking human solidarity we must also deny the person their human dignity (in the Natural Law sense) and fail to contribute to the common good. If the patient is conscious but unable to communicate their wishes then we must also accept that our decisions may result in extraordinary levels of mental agony.

Our case study demonstrates that non-voluntary euthanasia does occur and it seems that it is such a commonplace event that the Coroner didn't trouble themselves to investigate the matter further (see also Brock, 2012). Indeed, despite the evidence which the Coroner itself relates, the finding was that the case 'accords with good medical practice'.

The public policy implications arising from our case study and explication are profound.

First, this case study demonstrates that the present political debates (see, for example, Kennedy and Kennedy 2017) are ill-defined. The common law principle of double effect already absolves a medical practitioner of legal and moral culpability when a patient unintentionally dies (in the absence of medical negligence). In addition, patients and medical practitioners are already free to refuse futile medical treatment. Therefore the question which should be at the center of the political debate is whether doctors should be allowed to make acts or omissions with the intent to cause death. Yet as we have seen, these acts and omissions already occur in Australian hospitals. It is curious that so much political effort is being invested into the question of whether a patient might be free to direct a medical practitioner to act or omit to act with the 
intent to cause death, when the much more morally disturbing matter of non-voluntary euthanasia is being ignored, and it seems, tacitly condoned. Publicly acknowledging that nonvoluntary euthanasia does occur in Australia, that doctors are already protected from action related to unintentional death and that patients already have rights to refuse futile treatment seem to be important prerequisite for an informed debate.

Second, religious authorities clearly have to be proactive in participating in the community debate regarding euthanasia, the principle of double effect and proposals to change legislation. This is important because of the moral authority residing in religious institutions, but also because a good proportion of aged care facilities and hospitals are run by religious associations (including the one at which $\mathrm{X}$ died). The Catholic Church, as one of the inheritors of the Natural Law tradition has set out firm guidelines regarding end-of-life care in their facilities. However, many of the protestant churches and other religions have been conspicuously silent on the matter. Secular moral authorities are also 'missing in action' - notably the Australian Human Rights Commission 2016 (p.3) Issues Paper that acknowledges that 'euthanasia raises some of the most fundamental philosophical questions of all', but then specifically states that 'involuntary euthanasia is not considered'.

Third, there would seem to be a good case for education campaigns encouraging persons to complete advanced health directives which provide clear instructions on what procedures and care the person wishes to receive at end-of-life. Moreover, it seems to be an alarming oversight that there is no legislation in place to make the completion of advanced health directives (AHD) and enduring powers of attorney (EPA) compulsory for all admissions to aged care facilities and all persons admitted for palliative care. This is not about denying freedom, but rather about ensuring that persons have the opportunity and support (by way of counselling) to set out their wishes at times proximate to end-of-life, and that the completed instruments (AHD and EPA) are readily available when required.

Fourth, there is an obvious need for a defined and expedient avenue to resolve disputes regarding end-of-life care. The idea that all persons associated with palliative patients will get together in the room and come to a complete consensus is optimistic in the extreme particularly in the case of non-voluntary euthanasia. The Coroner's report on the events leading up to the death of X illustrate this point vividly - we are informed that the family were in heated dispute on the matter, hence the appeal to the Coroner. When a dispute does occur, particularly 
in the case where there is dispute on the palliative status of the patient, there needs to be some timely avenue of appeal and adjudication before death, not after.

Finally, if we are to give assent to euthanasia there would seem to be a clear need for statutory enforced guidelines on the conditions and protocols which must be met before persons are euthanized (Deliens, 2003; Brock, 2012; Angell, 1997). One would hope that these conditions would set out inter alia the support provided to the patient and family, timely and authoritative avenues for appeal when there is disagreement, the type of objective evidence required to support decisions that a person is palliative (which must be a pre-requisite of euthanasia), the number of independent medical specialists who must provide written support for the diagnosis, the acts and omissions which might be made to cause intentional death in the person, the indicators which must be used to determine whether the patient or those seeking to speak on behalf of the patient are competent for decision making purposes, the form of the request (preferably written) and the number of witnesses required to attest to the request, the duration of a 'cooling off period' subsequent to the request, the evidence required to confirm that the patient is subjected to pain and suffering, mechanisms for ensuring that economic considerations aren't allowed to influence the decision making of the patient, medical practitioners and families, and details on the information required for mandatory reporting of persons intentionally killed by medical practitioners (Deliens, 2003; Brock, 2012; Vogel, 2011). The reasons for most of these conditions revolve around ensuring that there is no doubt of the patient's palliative status, level of suffering, knowledge of treatments to reduce suffering, competency for making decisions, and no possibility of coercion. Moreover, it would seem important for regulation to also respect the dignity (in the Natural Law sense) of the medical practitioner - that is, the right of the practitioner to refuse to practice euthanasia must be protected (Angell, 1997). Mandatory reporting is required to ensure that there are no mistaken or intentional violations of public policy (Vogel, 2011). It is a rather curious fact that the scholarly and public debates generally focus on the rights and wrongs of allowing euthanasia, but pay scant attention to the comprehensive public policy controls which would be required to ensure that the practice is not abused.

In short, when one sets aside all of the rhetoric from both sides of the euthanasia debate and examines what actually happens in practice it is clear that the extant public policy debate exhibits far from desirable standards of deliberative inquiry and that much work remains to be done. 


\section{References}

Abrams, Natalie. (1978). Active and Passive Euthanasia. Philosophy, 53(204): 257-263.

Angell, M. (1997). The Supreme Court and Physician Assisted Suicide - the Ultimate Right. The New England Journal of Medicine, 336(1): 50-53.

Aquinas, T, 1989, Summa Theologiae, T McDermott (ed), Notre Dame, IN: Ave Maria Press Australian Human Rights Commission (2016). Euthanasia, Human Rights and the Law Issues Paper.

Barry, Robert (2004). The Papal Allocution on Caring for Persons in a "Vegetative State". Issues in Law \& Medicine, 20(2): 155-164.

Beabout, G, 1989, Morphine use for terminal cancer patients: An application of the principle of double effect, Philosophy in Context 19, 49-58

Boileau, David (1998). Principles of Catholic Social Teaching. Marquette University Press: Milwauke.

Brock, K. (2012). Controversial Policies and the Usefulness of Nonprofit, Private and Public Sector Partnerships: Introducing and Assisted Suicide Service in Ontario. Canadian Review of Social Policy, 67: 1-15.

Craig, G. (1994). On Witholding Nutrition and Hydration in the Terminally Ill: has Palliative Medicine Gone Too Far? Journal of Medical Ethics, 1994, 20: 139-143.

Craig, G. (1996). On Witholding Artificial Hydration and Nutrition from Terminally Ill Sedated Patients. The Debate Continues. Journal of Medical Ethics, 22: 147-153.

Drew, J. and Grant, B. (2017). Subsidiarity: More Than a Principle of Decentralisation - A View from Local Government. Publius, DOI: https://doi.org/10.1093/publius/pjx039.

Drew, J., Grant, B. and Fisher, J. (2017). Re-evaluating Local Government Amalgamations: Utility Maximisation Meets the Principle of Double Effect. Policy \& Politics 45(3): 379-394.

Emon, A., Levering, M. and Novak, D. (2015). Natural Law: A Jewish, Christian \& Islamic Trialogue. Oxford University Press: Oxford.

Finnis, John (2004). Founders: Aquinas. Oxford University Press: Oxford.

Finnis, John (2013a). Human Rights \& Common Good. Oxford University Press: Oxford. Finnis, John (2013b). Intention \& Identity. Oxford University Press: Oxford. 
Foot, P, (1978). The problem of abortion and the principle of double effect, in Virtues and vices and other essays in moral philosophy, Berkeley, CA: University of California Press

Garrard, E. and Wilkinson, S. (2005). Passive Euthanasia. Journal of Medical Ethics, 31: 6468.

Hittinger, Russell. 2003. The first grace: Rediscovering the natural law in a post-Christian world. Wilmington: ISI Books.

Kennedy, J. and Kennedy, M. (2018). The Other Side of Euthanasia: A Practice Perspective from Victoria'. Research in Ethical Issues I Organisations 20 (in print).

Lifton, R. (1986). Medical Killing and the Psychology of Genocide: The Nazi Doctors. United States: Basic Books.

McGee, Andrew. (2004). Double Effect in the Criminal Code 1899 (Qld): A Critical Appraisal. Queensland University of Technology Law and Justice Journal, 4(1): 46-57.

McLachlan, H. (2008). The Ethics of Killing and Letting Die: Active and Passive Euthanasia. Journal of Medical Ethics, 34: 636-638.

Messner, Johannes. 1952. Social ethics. Natural law in the modern world. Translated by J. J. Doherty. St Louis: B Herder Book Co.

New South Wales Government. (2017). Public Consultation Draft NSW draft non-government bill, Voluntary Assisted Dying bill, part 2, division 1 p. 2.

Pearce, C. and Duncan, H. (2002). Enteral Feeding. Nasogastric, Nasojejunal, Percutaneous Endoscopic Gastrostomy, or Jejunostomy: its Indications and Limitations. Postgraduate Medical Journal, 78: 198-204.

Queensland Courts, Office of the State Coroner. Coronial Investigation into the Death of X. Date and name withheld to assure anonymity.

Quinn, W, 1989, Actions, intentions and consequences: The principle of double effect, Philosophy and Public Affairs 18, 4, 334-51

Velasquez, Manuel and F. Neil Brady. 1997. Natural Law and Business Ethics. Business Ethics Quarterly 7(2): 83-107.

Victoria State Government, Dept Health \& Human Services (2017). Voluntary Assisted Dying Bill discussion paper. Retrieved from https://www2.health.vic.gov.au/about/publications/researchandreports/voluntaryassisted-dying-bill-discussion-paper accessed 16th July, 2017 
Vogel, L. (2011). Dying a "Good Death". Canadian Medical Association Journal, 183(18): 2089-2090.

YouTube (2017). Nasogastric Tube Insertion. Accessed 23 March, 2017 at: https://www.youtube.com/watch?v=en5ctZInOyA

YouTube (2017). IV Insertion (Real Time). Accessed 23 March, 2017 at: https://www.youtube.com/watch?v=8Hi4JNXdcHM 